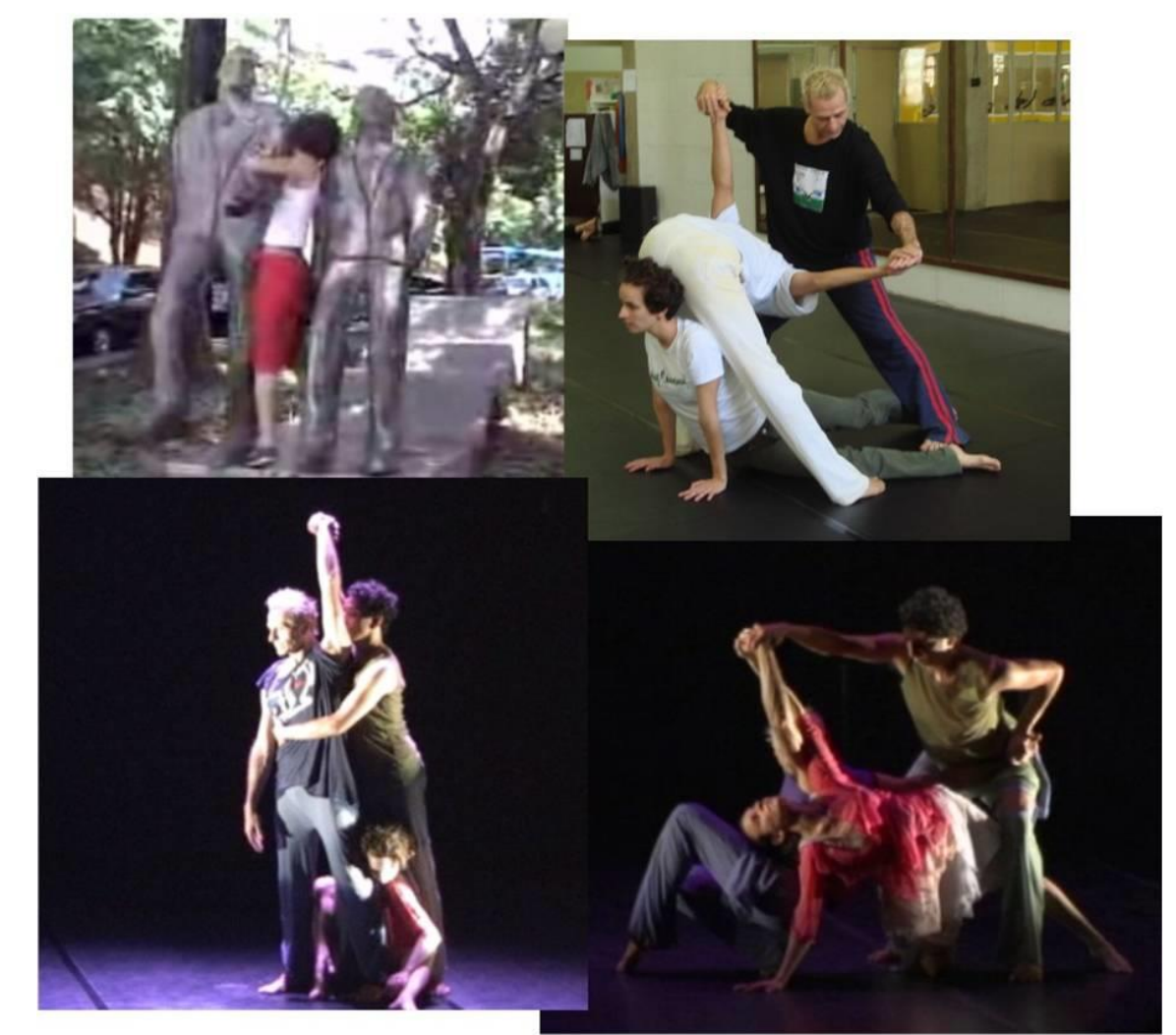

Ester França, VC6. Carlos Arão, Ester França e Fábio Dornas em ensaio em sala, ensaio no Teatro e espetáculo em BH.

\title{
Informação e corpo: uma dança entre o individual e o social (1)
}

\section{Anderson Fabian Ferreira Higino}

Professor do CEFET-MG; especialista em Ensino de Física pela UFMG; mestre em Educação Tecnológica pelo CEFET-MG; doutorando em Ciência da Informação pelo PPGCI/UFMG, com pesquisa sobre interdisciplinaridade e transdisciplinaridade; integrante do Programa de Ensino, Pesquisa e Extensão A tela e o texto (FALE/UFMG). (*)

\section{Graziela Andrade}

Doutoranda na École Doctorale Culture et Société (LSHSS, Paris-Est), em cotutela com a Escola de Ciência da Informação da UFMG; mestre em Ciência da Informação (UFMG, 2008); integrante do Núcleo de Estudos das Mediações e Usos Sociais dos Saberes e Informações em Ambientes Digitais (NEMUSAD). Sua pesquisa acadêmica está voltada, principalmente, para as aproximações entre corpos e novas tecnologias. 


\section{Resumo}

Com base na articulação de fundamentos teóricos da semiótica, das redes sociais e do pensamento complexo, são discutidas as relações que unem informação e corpo, no contexto do perene diálogo entre indivíduos e múltiplos níveis de organização social. Nossa jornada cibercultural tem como ponto de partida um experimento inovador, no domínio da criação coreográfica, e segue a trilha dos complexos desafios hoje presentes nas intrincadas experiências de leitura da realidade e de produção individual-coletiva de sentidos, projetos, biografias e histórias.

Palavras-chave: informação - corpo - semiótica - redes complexidade - cibercultura - movimentos sociais.

\section{Abrem-se as cortinas...}

A relação à primeira vista curiosa entre corpo e informação incita-nos a uma abordagem experimental que busca um diálogo entre os campos acadêmico e artístico. Quando integrada às atuais interfaces tecnológicas, tal relação torna-se ainda mais singular, o que amplia em muito o desafio de dar sentido às interrelações da tríade corpo-informação-tecnologia. Esse é um desafio com o qual, de todo modo, defrontam-se cada vez mais intensamente os participantes da cibercultura, se entendida do ponto de vista de Lemos (2), segundo o qual a técnica, a cultura e a sociedade contemporânea são vertentes abstratas complexas e indissociáveis.

Nessa jornada cibercultural, foi investigado o trabalho de quatro bailarinos envolvidos em um trabalho coreográfico inovador: Andréa Anhaia, Carlos Arão, Ester França e Fábio Dornas. O desejo de aproximar e praticar pensamentos sobre o movimento levou-os a por em diálogo suas distintas formações e expressivas afinidades artísticas. Foi assim que deram início, no ano de 2005, em Belo Horizonte, ao grupo Movasse, um coletivo de criação em dança cuja proposta materializou-se na manutenção de um espaço aberto ao trânsito livre de pessoas, informações e idéias relacionadas à dança contemporânea.

A convivência social prévia com os integrantes do Movasseabriu aos autores a possibilidade de acompanhar, num dos projetos do grupo, toda a etapa de concepção individual dos movimentos e, posteriormente, realizar entrevistas com os bailarinos. O objetivo fixado foi sondar como eles percebem o uso e as trocas de informação nessa experiência de produção. o projeto focalizado foi a pesquisa coreográficalmagens Deslocadas, que 
surgiu em uma situação na qual os bailarinos viram-se impossibilitados de realizar encontros presenciais para conduzir determinado processo de criação. Essas circunstâncias levaram-nos a uma solução inovadora: a corajosa opção pelo uso de interfaces tecnológicas como forma de interação que lhes possibilitaria levar a cabo o trabalho. Os integrantes do Movasse inventaram, assim, o formato Vídeo-Carta(3), com base na seguinte ideia: cada um escolheria um ambiente, elaboraria e registraria em vídeo seus movimentos e, em seguida, publicaria o resultado em um site de acesso livre na web. Essas "postagens" possibilitariam a cada bailarino acompanhar as composições dos demais parceiros, tornando-se a base de uma dinâmica de criação interativa e iterativa.

$\mathrm{Na}$ primeira fase do projeto, cada bailarino assumiu o compromisso de gravar e postar no YouTube uma Vídeo-Carta por semana. Correspondendo-se dessa forma, eles se lançaram num processo no qual cada qual devia responder, com seus movimentos, aos movimentos dos parceiros, buscando identificar-se com o outro e com os espaços por ele escolhidos. Assim seguiu a correspondência, até se completarem 32 cenas, com 8 Vídeo-Cartas de cada bailarino. É importante destacar que a interação mantida entre eles, nessa fase do processo criativo, ocorria exclusivamente por meio da web. (4)

$\mathrm{Na}$ segunda fase, deu-se a concepção do espetáculo Imagens Deslocadas, com os bailarinos enfrentando o desafio artístico de resgatar e transpor a percepção do lugar, as sensações experienciadas e os movimentos que cada um gerou, de modo a organizar, numa montagem de dança contemporânea, toda a informação relacionada à correspondência. O corpo, em sintonia com os elementos cênicos, tornou-se o veículo central de tradução dessa experiência de diálogo - iniciada virtualmente - do ciberespaço para o palco e, mais ainda, para um público espectador com leituras variadas.

\section{Primeiro movimento: semiótica}

No contexto empírico constituído por essa experiência criativa, e no intuito de colaborar com o levantamento e a fundamentação de questões sobre as relações pertinentes à tríade corpo-informação-tecnologia, pensadas nas perspectivas individual e social, buscamos, como um primeiro movimento, o aporte teórico de conceitos que refletem o ponto de vista semiótico, no tratamento dos temas corpo e informação.

Helena Katz(5) propõe a existência de uma relação evolutiva entre organismo e meio, na qual homem e natureza coevoluem, sendo o corpo postulado como mídia básica dos processos de 
comunicação da natureza. Segundo a autora, as possibilidades de armazenagem, transmissão e interpretação de informação, superficialmente falando, remetem à hereditariedade, à constituição da vida em suas estruturas de replicação. As transformações desses processos informacionais seriam uma exigência da maior complexidade da vida, tornando-se o corpo um lugar privilegiado, no que diz respeito à explicitação da evolução e do relacionamento entre natureza e cultura.

Corpo é mídia, nada além de um resultado provisório de acordos cuja história remonta a alguns milhões de anos. Há um fluxo contínuo de informações sendo processadas pelo ambiente e pelos corpos que nele estão.(6)

Essa abordagem propõe, assim, pensar o ser vivo como processador de informação entre o ambiente circundante e seu interior. No caso humano, o corpo agiria, por meio dos sentidos físicos, como uma espécie de tradutor de informação, mas essa é uma característica que se estenderia a qualquer ser vivo, pois todos eles seriam capazes - cada qual a seu modo de processar as informações que lhes advêm do meio. Citando o biólogo Jakob Von Ueküll e duas expressões por ele cunhadas, Katz (7) opõe Umwelt - referente ao universo subjetivo ou do self - a Umgebung - relacionada ao meio ambiente, ao externo - para afirmar que todos que transpõem para dentro o que está fora produzem mundos interiores.

Mencionando o mesmo biólogo, o semioticista Júlio Pinto (8) descreve 0 mundo interiorizado - InnenWelt - como resultado das impressões produzidas pelo mundo exterior LebensWelt - no aparato cognitivo de uma espécie, constituindo um mapeamento ou chave de decodificação da informação externa. Para esse autor, o que distingue o homo sapiens das outras espécies processadoras de informação é a capacidade decogito, de reflexão, a habilidade denominada "processamento de signos". (9) Essa questão será retomada mais adiante. 

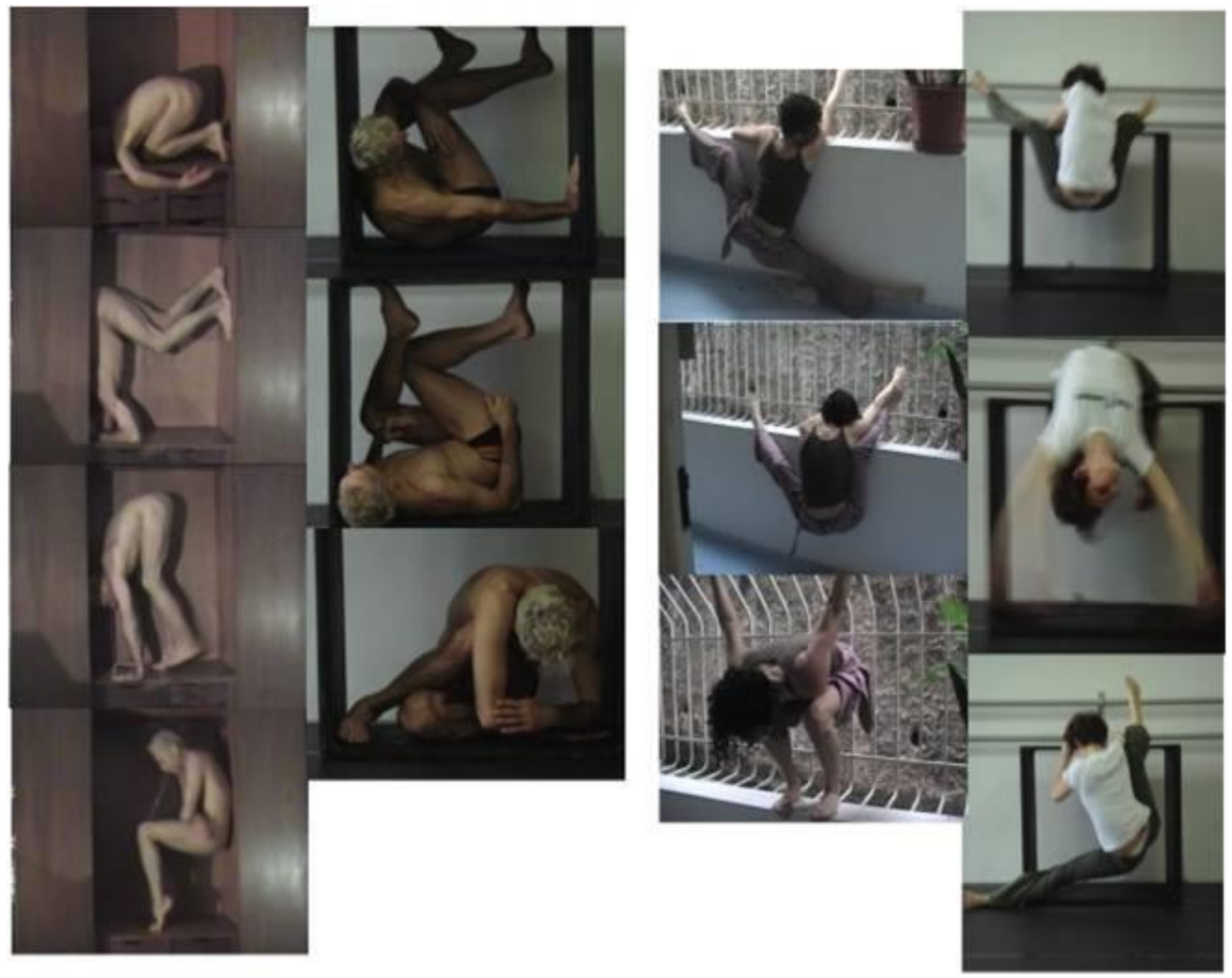

Carlos Arão, VC6 e ensaio em sala. Ester França, VC5 e ensaio em sala.

No entendimento de Katz (10), o trânsito entre o dentro e o fora diz respeito a todas as instâncias do corpo, e o cérebro seria o comandante principal das ações desse corpo, situado num contexto irrigado por informações plurais capazes de promover novas percepções para velhas questões. Para a autora, a indeterminação do cérebro é sua força maior, pois assim é que ele se adapta ao corpo no qual se encontra. Daí a idéia de processo de evolução e desenvolvimento constante e complexo. A coevolução do cérebro daria, portanto, ao corpo o mérito das conexões para o entendimento das relações entre natureza e cultura. Mas é preciso lembrar aqui duas questões: o homem está inteiramente implicado naquilo que observa; a cultura não é uma ação exclusiva do homem sobre a natureza.

o homem não se encontra inserido nessa dinâmica como um sujeito passivo posto ali, nem simplesmente cumprindo a função de objeto receptor, mas sim como produto e produtor que, ao interagir na relação, tem na informação um mediador e em seu próprio corpo, um decodificador, processador, armazenador e transmissor dessa mesma informação, que o conformará como indivíduo. Ou seja, o corpo forma-se a partir de sua própria ação processadora de informação, que, ao mesmo tempo, dá forma e identidade ao sujeito possuidor desse corpo. 
Os dois autores parecem concordar quanto à forma pela qual isso se dá: o modo de interação do ser humano no mundo, a qual aconteceria, para ambos, no fluxo dos processos semióticos, analisados por meio do conceito de signo de Peirce. Sobre essa teoria, Helena Katz (11) esclarece que o signo é um tipo especial de conexão física que qualquer evento possui com o objeto que representa. Complementarmente, Júlio Pinto (12) afirma que, além de computar biologicamente a informação que advém do meio ambiente por via sensorial, o homem usa essa informação e também a "re-produz", para prever um futuro estado de coisas. Sem nenhuma pretensão de preciosismo quanto à definição de signo e focalizando o aspecto informacional nela contido, partimos do pressuposto de que informações chegam a nós por meio de signos, em um processo complexo e contínuo de produção de sentido inerente à percepção do indivíduo.

No entanto, esse ser individual que percebe é também social e integrante de determinada cultura e coletividade. Segundo couchot (13), uma das fascinações que as tecnologias exercem sobre nós é que, para a experiência sensível, interessa não o EU e, sim, o outro. O autor chama experiência tecnestésicaà situação na qual o sujeito, ao usar determinada tecnologia, inclui sua singularidade e vive uma experiência íntima que transforma sua percepção de mundo. Essa experiência, essencialmente perceptiva, é vivenciada em um modo onde o EU está ausente. A percepção se dá sempre no modo do Nós, que é um sujeito despersonalizado e indefinido, mas que não está fora da história e da linguagem, ou fora da cultura e das relações de poder. As tecnologias forçam-nos a ser mais frequentemente Nós do que EU. A experiência tecnestésica gera sensações e atividades comuns, mas não pessoais. Ao conduzir um automóvel, por exemplo, o sujeito EU vive uma experiência perceptiva comum a milhares de outros motoristas e para a qual não podemos apontar autores. Nesse contexto, quaisquer sejam os indivíduos, psicologias e idiossincrasias de uns e outros e suas memórias ou idéias, o uso das técnicas conformará cada um segundo um modelo perceptivo partilhado por todos, ou seja, um habitus comum que dá base à elaboração de uma cultura da qual a arte se alimenta. (14)

Cuche (15)esclarece que a noção de habitus, proposta por Bourdieu, refere-se ao condicionamento de certos modos de vida, que distinguiria e caracterizaria grupos sociais. Ohabitus manifesta-se no âmbito da materialização de uma memória coletiva e, por ser profundamente interiorizado, não exige esforço consciente dos indivíduos. Além disso, é objetivamente adaptável, ou seja, em novas situações ou diante de outras técnicas, o habitus apresenta flexibilidade em relação ao desempenho de outras funções. 
Se, conforme afirma couchot (16), a arte alimenta-se da cultura e esta, por sua vez, é elaborada a partir de umhabitus comum, podemos tomar essa proposição como base para elucidar diversas "coincidências" que os bailarinos mencionam ter ocorrido no processo de produção das Vídeo-Cartas. Para o mesmo autor, a atividade artística colocaria em jogo um sujeito-Nós modelado pela experiência tecnestésica e um sujeito-EU, com o resgate de uma subjetividade irredutível às tecnologias e ao habitus.

No primeiro momento de construção coreográfica do projetolmagens Deslocadas, o bailarino atém-se individualmente a suas percepções, em um ambiente por ele recortado, e age, nesse espaço, recebendo e registrando informações por meio de signos que ora signi-ficam, ora signi-vão... (17) Nesse momento, ele reage movimentando-se a partir de práticas de dança adquiridas de acordo com sua vinculação social. Quando divide essa experiência - já coletiva - com o grupo, que é marcado por um habitus comum e, portanto, possuidor de uma mesma concepção de mundo "incorporada", dá-se um notável processo de múltiplos e mútuos reconhecimentos, capaz de gerar percepções e sentidos semelhantes e de provocar uma convergência dessa dança de signos e significações.

A homogeneidade dos habitus do grupo faz que um se reconheça no movimento do outro e proponha, de modo i(n)terativo, um movimento subsequente que, novamente, será reconhecido e percebido por todos, num ciclo criativo de significações no qual se dá um exercício de percepções necessariamente enriquecido tanto pelo individual quanto pelo social. 0 indivíduo não é negado nesse processo. Aliás, parece estar nele o maior encanto da criação na dança, pois é o corpo de cada um que vai processar informações - semelhantes e diferentes - e produzir movimentos completamente distintos. Ainda que houvesse um esforço coreográfico de igualar as reações, por meio de movimentos harmônicos, esses seriam únicos e pertencentes ao EU integrador do Nós, conformado emhabitus, mas exclusivo em suas ações. 


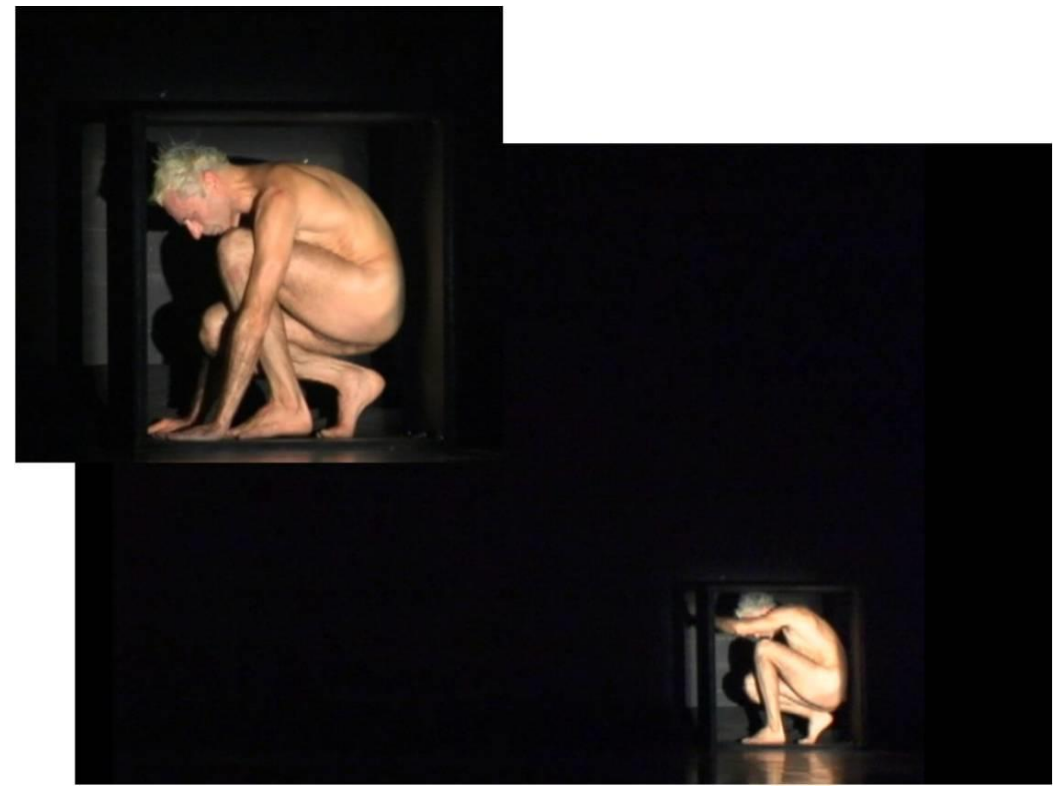

Carlos Arão em detalhe, apresentação em SP.

\section{Segundo movimento: complexidade, redes}

Em complementação à abordagem semiótica, buscam-se noções referentes à complexidade e às redes, a fim de enriquecer a percepção de aspectos sugeridos pela dinâmica do projetolmagens Deslocadas. A estrutura deste segundo movimentocombinará cada um dos elementos em discussão - corpo, informação, dança - com o intervalo de níveis de análise eleito - entre o individual e o social. Em relação à dança, essa expressão pode também indicar que os passos e movimentos dão-se sempre como uma "parceria" entre os dois níveis extremos desse intervalo.

\section{Corpo: entre o individual e o social}

Ao tomar o corpo como metáfora de uma harmonia que se esperava prevalecer na sociedade, a sociologia funcionalista inaugurou uma forma otimista de pensar o conjunto dos fenômenos sociais, visto como resultante de uma integração interdependente de partes com funções diferenciadas e necessárias ao equilíbrio do todo. De acordo com essa concepção, cada novo indivíduo deve ser integrado - corpo e mente - ao todo social, por meio do processo de socialização realizado pelas instituições, principalmente por aquelas ligadas à educação, tais como a família e a escola. O objetivo desse processo é a garantia da reprodução da harmonia concebida como ideal. (18) 
Discutindo o corpo como objeto social, Maria Rita Kehl (19)traz uma esclarecedora abordagem sobre seu processo de civilização, a partir dos manuais de civilidade, tais como aquele escrito por Erasmo de Rotterdam, em 1530. O pequeno livro ensina a cortesia, conjunto de normas de contenção que estabelecem os sinais de distinção social necessários à boa aceitação numa Europa moderna onde começava a aumentar a intensidade das interações com estranhos vindos de outras terras e pertencentes a outras classes sociais. Os exemplos usados descem a detalhes que podem revoltar os estômagos mais sensíveis, com o intuito de ilustrar como foi necessário ensinar os europeus daqueles tempos a comportar-se de modos e maneiras que são concebidos hoje, em geral, como absolutamente "naturais". Fica nítido que esses "bons modos" decorreram de um longo processo de disciplinamento do corpo, também realizado em paralelo, no âmbito do pensamento, pelo cristianismo. Esse intrincado processo histórico-social de con-formação do corpo-mente individual levou à produção de noções tais como o "bom gosto", que revelam, por trás de si, em entrefalas e entreatos, refinados dispositivos de contenção e repressão que, agindo sobre indivíduos, estendem-se a níveis mais amplos, articulando-se numa con-formação das partes do "corpo social" produtora de harmonias supostamente naturais.

Maria Cecília Pilla (20) apresenta outra instrutiva análise crítica de famosos manuais de civilidade escritos entre os séculos 16 e 19, tomando-os como códigos de boas maneiras que refletem as ideias de moralidade, delicadeza e polidez típicas dos modelos civilizatórios aos quais se filiam. Vale comentar que alguns desses livros continuam sendo publicados até o presente e encontram-se disponíveis em livrarias e bibliotecas, juntamente com outras obras congêneres, escritas ao longo do século 20 e mesmo nos dias atuais. É possível inferir que integram essa tradição os tantos manuais de etiqueta cujos códigos "sancionam" as condutas aceitáveis em ambientes tão diversos quanto o restaurante "fino", a mesa de negócios ou a reunião diplomática. Vê-se, assim, que os contextos de condicionamento vinculados a essas obras podem se estender desde o círculo social mais próximo até a esfera geopolítica. 


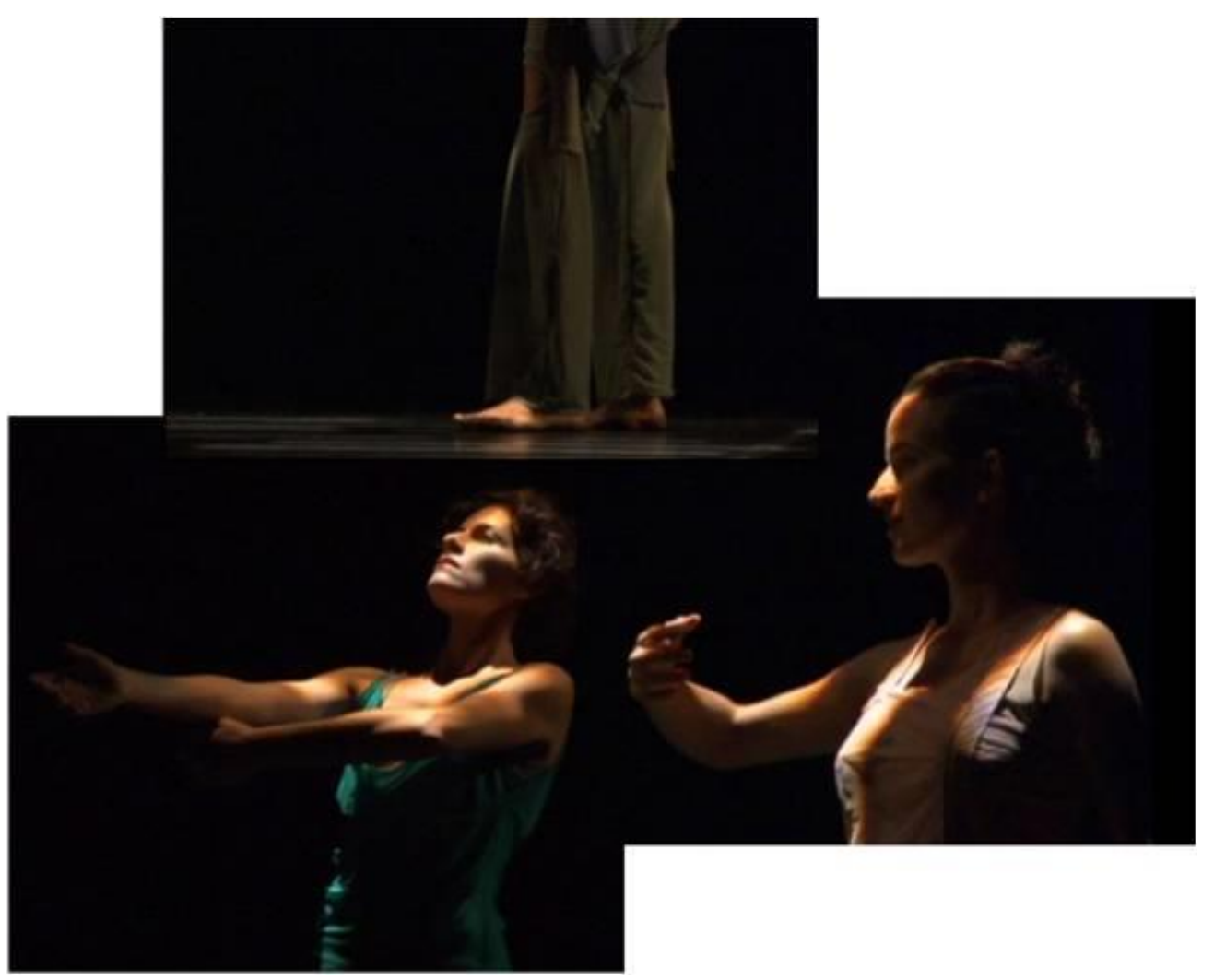

"Retalhos" de luz em detalhes

Por meio do conceito de habitus, também Pierre Bourdieu trata dessas disposições estruturadas via condicionamento e estruturantes de comportamentos e modos de vida que caracterizam os grupos sociais e diferenciam-nos uns dos outros. A noção engloba as disposições corporais, vistas como "incorporação" de uma memória coletiva. Ainda que não preconize uma visão fixista, a proposição de Bourdieu ajuda a compreender a origem do apego a muitos comportamentos socialmente includentes e excludentes atribuíveis a classes, tal como se dá no contexto da cultura burguesa (21).

Essa linha de reflexão leva a perceber as harmonias e as tensões do corpo social como construtos históricos e, principalmente, a opção preferencial pela discussão a partir destas ou daquelas como fruto de distintas escolhas teóricas. Se o funcionalismo focalizou harmonias, o pensamento crítico analisou as configurações mais retesadas do corpo social, procurando legitimar as tensões reveladas nas relações de classes como fontes de potência e criatividade. Desse ponto de vista é que, em lugar de uma socialização harmônica, os movimentos sociais foram colocados no centro da cena histórica. 
Em discussão recente, Alain Touraine (22) faz um alerta sobre a fragmentação, a decomposição desse corpo social, sob ação das forças não-sociais da economia globalizada e face às tensões da violência e da guerra. Em vista disso, propõe às ciências sociais um paradigma que ajude a compreender a passagem da potência motriz do social ao cultural. A noção de sujeito está na base dessa nova dinâmica social, que, em lugar das grandes massas, envolverá indivíduos e coletividades que lutem por maior autonomia na condução dos próprios destinos. Nessa concepção, conectam-se novamente o corpo individual, em busca de integridade e expressão, e o corpo social, fragmentário e sem um autocontrole tão definido e definitivo quanto antes se chegou a pensar. A atenção à sexualidade, força criativa básica da vida humana, é sinalizada como ponto central da relação consigo mesmo e com o outro, perspectiva que sugere uma virada de mesa no antigo jogo de dominação do masculino sobre o feminino, com o reconhecimento, nas mulheres, de condições para protagonizar a construção de uma sociedade nova e mais complexa.

Se Touraine aborda temas valiosos, talvez isso se deva, em parte, ao fato de seu esforço teórico pautar-se pelo cenário de marcantes desafios que caracteriza a própria atualidade da França. De formas diversas, suas páginas refletem muitos dos dilemas cotidianos vivenciados por aquela sociedade, diante do contraponto latente ou explícito entre liberdade e vigilância, igualdade e xenofobia, fraternidade e privilégio. Mesmo nesse cenário de tensão entre "civilização" e "barbárie", ecos de uma tradição histórico-cultural de vasto alcance parecem criar em Touraine uma resistência mais forte que a de outros autores ao discurso sobre a pós-modernidade. No entanto, apesar de mostrar-se assim tão cioso da importante herança da modernidade, o autor ainda consegue discutir com lucidez e pertinência algumas das questões necessárias à reflexão sobre o momento atual.

De todo modo, é importante cotejar a abordagem de Touraine com - pensamento de outros teóricos, tais como Boaventura Santos (23), que transita com muito maior liberdade por entre noções relacionadas à pós-modernidade - numa visão não celebratória, conforme esclarece - e à tradução intercultural, em seu esforço de propor uma visão compreensiva e mobilizadora sobre os desafios hoje enfrentados pelos grupos sociais e pelos praticantes das ciências sociais que se pretendam engajados nas inescapáveis lutas contra-hegemônicas e na própria reinvenção da ideia e dos ideiais de emancipação. Em artigo sobre políticas de informação, Higino et alii (24), além de abordar o pensamento de Boaventura Santos, em articulação com outros teóricos das Ciências sociais, também ilustram até que ponto faz diferença a escolha do referencial teórico, em termos das percepções sobre a realidade que podem 
ser explicitadas ou ocultadas e das possibilidades de ação e articulação social que podem ser potencializadas ou inibidas.

Edgar Morin (25) também contribui para a reflexão sobre corpos sociais percebidos como fragmentários e desafiados a enfrentar as complexidades e ambivalências dos ambientes naturais/culturais que pretenderam submeter à delirante racionalidade abstrata de uma dominação sem limites. Nesses ambientes, locais e globais, circuitos complexos tais como cérebro/mente/cultura e indivíduo/sociedade/espécie são propostos como estruturas explicativas das múltiplas conexões que é necessário educar-se e educar para compreender, com vistas a aprender a lidar, de modo consequente, com os processos e movimentos cuja emergência elas ensejam, num futuro que se faz cada vez mais presente.

\section{Informação: entre o individual e o social}

Ao tecer considerações sobre a figura do narrador, Walter Benjamin (26) relaciona à sequência narrativa-romanceinformação a passagem histórica de um saber de cunho oral, baseado em antigas tradições, primeiro ao relato escrito de grandes e belas histórias que interessavam à burguesia ascendente e, depois, às formas escritas baseadas na notícia sobre os acontecimentos próximos. Diferentemente dos anteriores, esse último gênero aspira a uma verificação imediata e baseia-se em aspectos tais como explicação e plausibilidade. Trata-se da literatura de informação, que, inicialmente materializada em jornais e revistas, ampliou sua importância no decorrer do século 20, abrindo, ao lado do rádio e do cinema, um disputado espaço para veículos cada vez mais baseados em tecnologias eletrônicas.

Da mesma literatura de informação e de seus desenvolvimentos e percalços trata Edgar Morin (27), ao discutir algumas das formas pelas quais o componente alucinatório inerente à percepção humana foi explorado por grupos e regimes de poder que souberam criar ilusões de explicação e plausibilidade suficientemente bem urdidas para alimentar a construção de mitos. Em cenários desse tipo, transcorrem processos nos quais assume um papel fundamental a competência para manipular a informação, sejam quais forem os meios de divulgação. Para evitar armadilhas do tipo, é necessário desenvolver competências específicas para uma leitura cuidadosa e uma ampla contextualização da informação. Nesse sentido é que Morin (28) também discute a relação entre informação e ideologia, estabelecendo uma diferença básica entre teoria e doutrina, em termos da abertura ou do fechamento demonstrado em relação à informação não-conforme. Seja entre educadores ou 
líderes políticos, tais reflexões são de uma importância inegável.

Nos dias atuais, para além de entender essas noções teóricas e usá-las no balizamento de novas compreensões, é imprescindível um esforço de reeducar o olhar e a percepção para demandas de leitura que se tornam cada vez maiscomplexas. Essa complexidade manifesta-se no sentido de o leitor ser desafiado a lidar com uma diversidade de elementos de significação - verbais, sonoros, imagéticos e mesmo táteis, olfativos e gustativos, em certos casos - que são tecidos juntos, de modo sinestésico e inextricável, na composição dos textos multifacetados que passam hoje não mais apenas a chegar-lhe aos olhos, mas a alcançar e abarcar todo o corpomente.

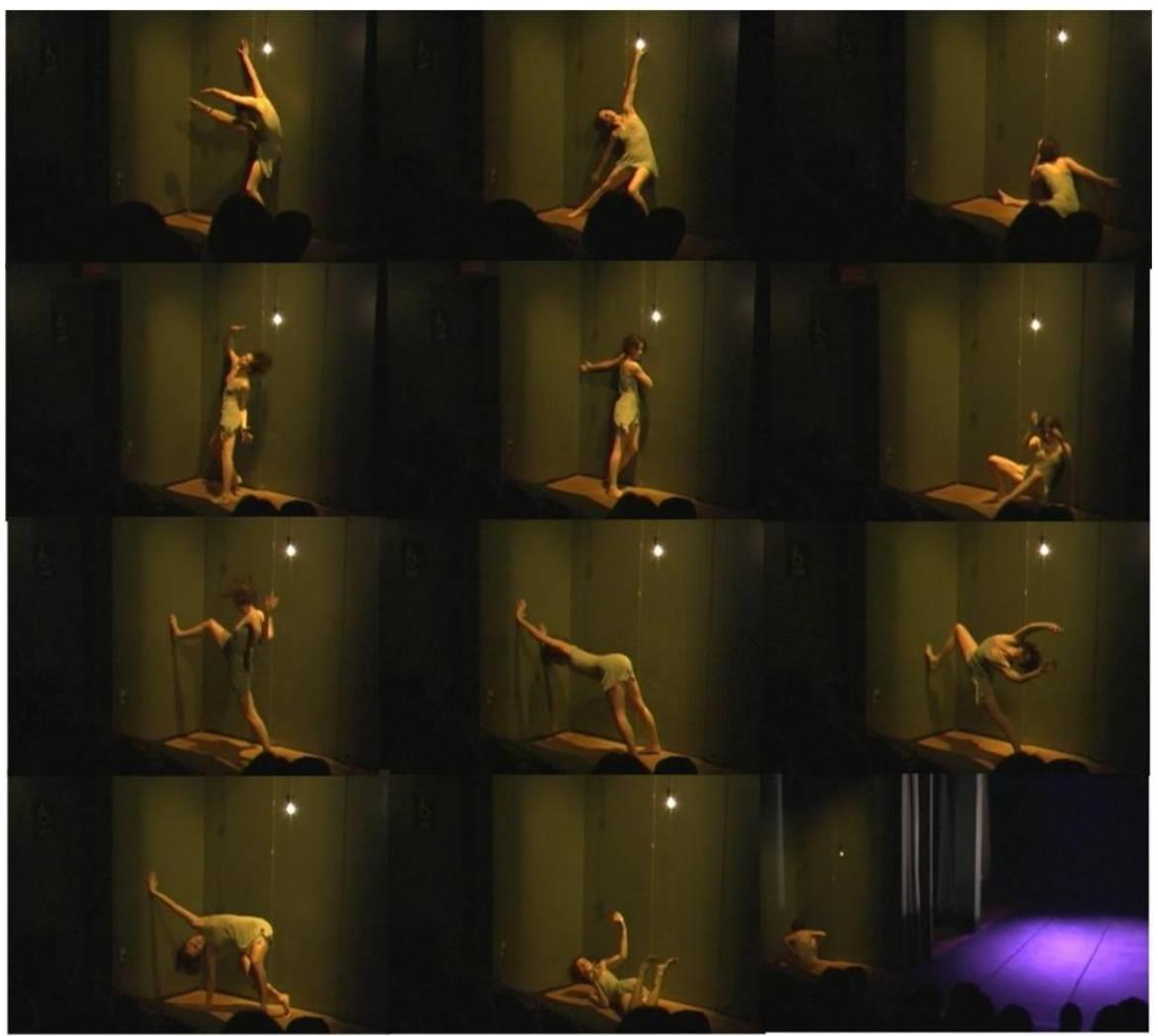

Andréa Anhaia, espetáculo em Belo Horizonte.

Esse desafio torna-se particularmente intenso num cenário no qual indústrias tais como a da publicidade começam a explorar, das formas mais diversas e criativas, a noção de que o ser humano - conforme assinalam Helena Katz (29) e Júlio Pinto (30) - é eminentemente informacional em suas relações com o meio no qual se insere. A profundidade alcançada por esse imbricamento complexo entre novas leituras e textualidades leva a perceber a necessidade de análises, 
reflexões e posicionamentos muito atentos e cuidadosos perante os discursos que alardeiam - de formas tão otimistas quanto interessadas - as virtudes e vantagens da dita "sociedade da informação". Constitui um imenso desafio pedagógico atender, de modo crítico-esteticamente adequado, às novas competências e funcionalidades exigidas dos processos de alfabetização e letramento, nesse "admirável mundo novo". Aos educadores ciosos da responsabilidade de seu fazer pedagógico, essas reflexões sugerem que as "gramáticas" dos tempos atuais definidas em meio aos jogos de poder que estabelecem o prescrito e o proscrito - exigem conexões de profundo caráter ético e político entre o aprender, o ensinar e o viver.

Edgar Morin (31) reitera o chamado de atenção quanto à importância dessa discussão. Por meio da fórmula parafrásicacomputo ergo sum, ele atribui ao ser humano um "funcionamento" baseado no "cálculo", na "computação" de informações. Estas, no entanto, vão muito além do componente racional, conforme assinalado por outra fórmula - homo sapiens/demens -, com a qual o autor destaca o jogo indissociável de razão e emoção presente no desenrolar dos processos humanos individuais e sociais. Nessa linha, Morin faz um lúcido alerta sobre que, em vez dos pequenos desajustes manifestados por tantos indivíduos em relação às regras sociais, é a própria racionalidade abstrata que constitui o verdadeiro sonho delirante. De acordo com o autor, é sempre no âmbito do circuito cognitivo complexo cérebro/mente/cultura que ocorre o "processamento" dessa informação racional/emocional que corresponde aos processos mesmos da vida humana. 


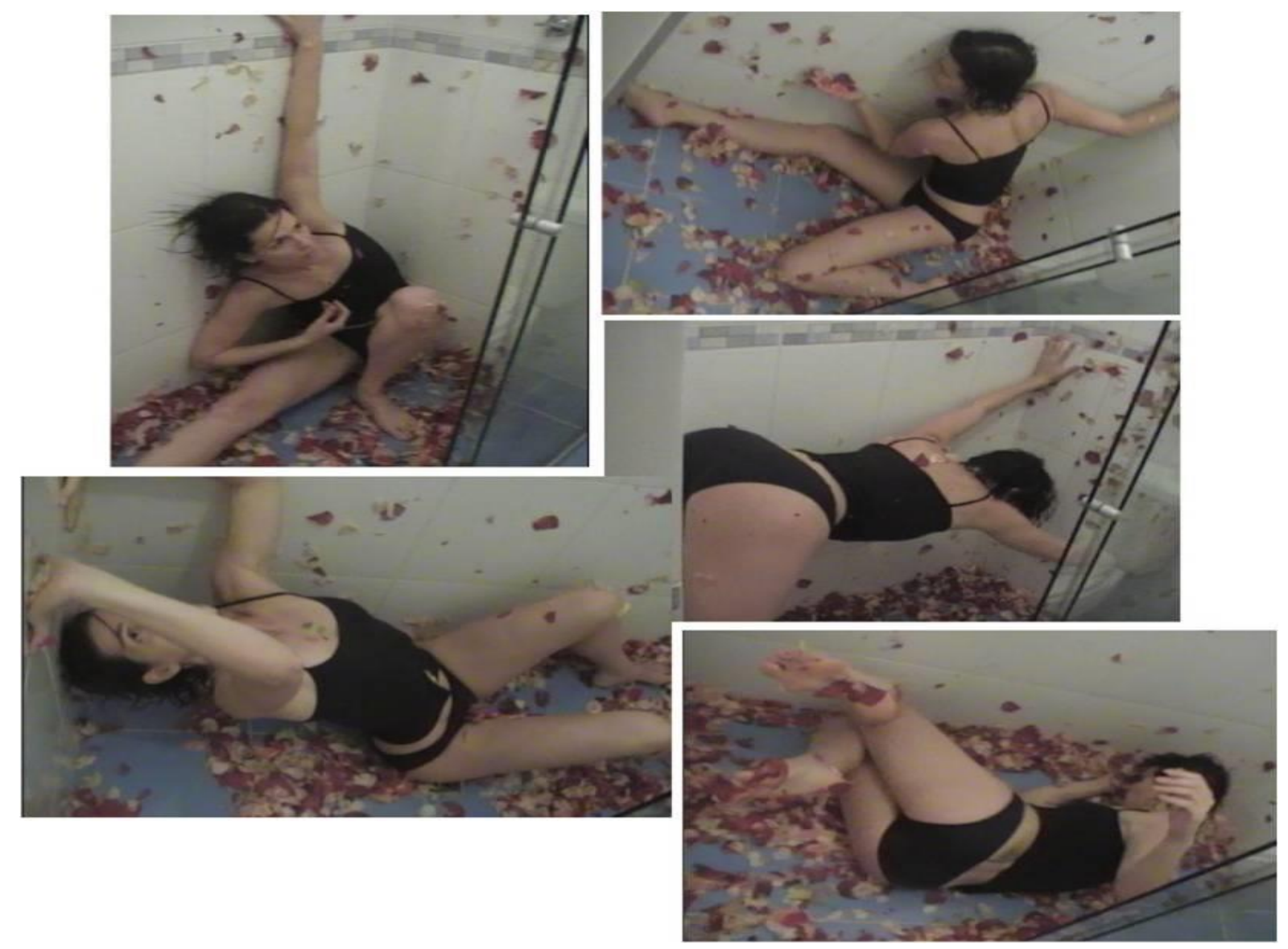

Andréa Anhaia, VC6.

Conquanto essa trilha leve o autor a convidar-nos ao envolvimento com a desafiadora construção de uma epistemologia complexa, nossa meta aqui é muito mais modesta: focalizar a informação como objeto complexo ligado a fenômenos que transitam entre o individual e o social e conectam elementos tais como corpo-mente, arte, dança, cultura e tecnologia, num contexto de múltiplas interações, expressões e leituras. A consideração exclusiva aos aspectos físicos/técnicos é, de longe, insuficiente à compreensão ampla que o próprio fenômeno demanda. É no âmbito do circuito complexo físico-cognitivosocial que, num contexto tal como a dança, o corpo-mente exercita múltiplas funcionalidades simultâneas, dentre as quais processador e mídia, conforme já assinalado.

Reitera essa perspectiva a proposta desenvolvida por Elin Jacob e Hanne Albrechtsen (32), ao analisar as consequências de abordagens teóricas inovadoras para a reflexão sobre sistemas de classificação de informação. Na trilha de análises desenvolvidas por teóricos tais como Mikhail Bakhtin e Michel Foucault, a noção pós-estruturalista de comunidades discursivas é usada para estabelecer elementos de uma teoria ecológica na qual a informação é vista não como coisa ou 
essência, mas como propriedade emergente da interação entre representantes de distintos grupos sociais. É à luz da proposta pragmatista da mescla entre tensão e diálogo na interação entre esses grupos que as autoras sugerem buscar caminhos para pensar os fenômenos informacionais, nos contextos reais criados pela condição e pela convivência humanas.

Nessa perspectiva social complexa, vivências e fenômenos corporais e informacionais devem ser concebidos em termos de uma noção de comunidade que não implique apenas o fechamento em torno do que é comum, mas admita, pelo contrário, abertura ao que é incomum, distinto, diferente. Essa parece uma condição necessária para evitar pretensões a uma homogeneidade que, em termos humanos, não passa mesmo de um sonho delirante, que tende muito rapidamente a revelar-se pesadelo. Por outro lado, a pretensão a que a informação se torne fator de mudança social pode tomar por base a orientação de evitar generalizações artificiais e buscar a dosagem humanamente possível entre o particular e o universal. Essa linha de reflexão remete a formas de organização nas quais o jogo entre autonomia e heteronomia permita um trânsito não destrutivo mas, possivelmente, desconstrutivo e reconstrutivo - entre regras comunitárias e princípios gerais, propiciando o vislumbre e a construção de cenários futuros de maior dignidade humana.

Desse ponto de vista, são diversos os campos de pesquisa que podem oferecer contribuições relevantes à descoberta de caminhos adequados, e necessariamente múltiplos, para a definição de projetos e programas nos quais as ações locais e as políticas públicas experimentem mais encontros do que desencontros. Abordagens tais como a das redes sociais, possivelmente aliadas a inspirações advindas do pensamento complexo e de pesquisas sobre sistemas complexos, parecem ter à frente um amplo horizonte. Mesmo porque conceber o ser humano como foco de iniciativas que envolvam um nível microsocial de organização e autoorganização exige abordagens informacionais e comunicacionais que possam ir além dos parâmetros tradicionais de hierarquia social.

No campo econômico, por exemplo, dentro de uma lógica radicalmente distinta da que anima a globalização neoliberal, iniciativas ligadas ao conceito de microcrédito passaram a ter um destaque inaudito. O Prêmio Nobel da Paz de 2006 foi concedido ao professor e economista bengalês Muhammad Yunus e ao Grameen Bank, que fundou em Bangladesh, em 1976. A instituição, conhecida como "banco dos pobres", conseguiu estabelecer, num país muçulmano, um sistema de concessão de micro-financiamentos voltado a grupos de mulheres pobres, sem exigência de garantias econômicas e com agentes de orientação 
e acompanhamento que contribuem para potencializar os efeitos dos investimentos. Essas e outras características ajudam a gerar resultados sócio-econômicos significativos, com expressiva melhoria da qualidade de vida dos beneficiários, constituindo um sistema auto-sustentado em expansão, com taxa de inadimplência virtualmente nula. OGrameen Bank já atua em dezenas de países e surgiram outras iniciativas congêneres, inclusive em terras brasileiras.(33)

E o Brasil tem também outras boas histórias a contar, em termos de economia solidária. Um dos exemplos dignos de nota é protagonizado pela comunidade do Conjunto Palmeira, bairro popular da periferia de Fortaleza, no Ceará. Para enfrentar a pobreza e a exclusão socioeconômica que os afligiam, os moradores organizaram e articularam uma série de esforços: mapeamento da produção e do consumo locais; montagem de um balcão de empregos; abertura de uma Incubadora Feminina, com espaços de produção e capacitação. A organização alcançou tal maturidade que possibilitou fundar, no final da década de 1990, o Banco Palmas(34), organização solidária que emite e controla a palma, moeda social com lastro em reais e circulação local autorizada pelo Banco Central do Brasil.(35) A criação da palma constitui, para a comunidade, um fator de múltiplos benefícios interligados: propiciar a inclusão socioeconômica de moradores que não têm acesso fácil à moeda oficial do país; dinamizar a geração local de oportunidades de emprego e renda, estimulando e facilitando a mediação entre oferta e demanda de produtos e serviços; ampliar a geração de poupança, evitando a "exportação" excessiva de riqueza localmente produzida no processo de "importação" de produtos e serviços vindos de fora.

As iniciativas descritas claramente não se lastreiam apenas nos princípios da economia bancária tradicional. As inovações introduzidas nessas combinações de empreendedorismo e protagonismo individual e social direcionam o foco firmemente para o ser humano, e não para o capital financeiro. E é importante perceber como as investigações e ações necessárias à realização de projetos assim envolvem um o esforço articulado de leitura, releitura e reconstrução ativa da autoimagem, da identidade comunitárias e da realidade social. Nesse âmbito, a produção e o uso da própria informação também seguem outra lógica, bem mais afinada com os mecanismos de (auto)organização social e econômica que as comunidades beneficiadas vão descobrindo e inventando. 


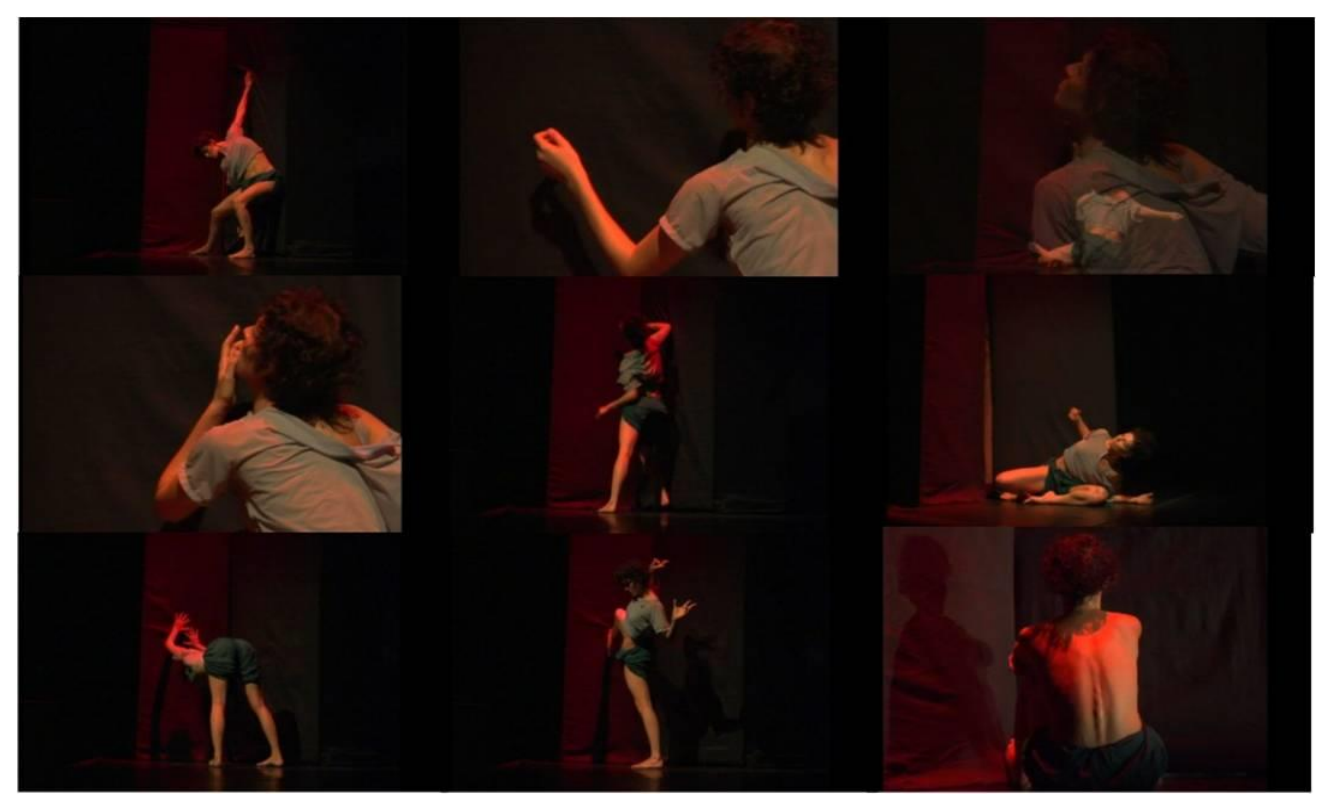

Andréa Anhaia, espetáculo em SP.

Mas o povo brasileiro tem ainda outros exemplos a apresentar. A fim de facilitar a identificação dos muitos locais que dão lugar a mais dessas pequenas grandes histórias, o Fórum Brasileiro de Economia Solidária(36)coloca à disposição do ciberleitor o "Farejador da Economia Solidária". (37) Trata-se de um mecanismo de busca associado a uma base de dados sobre boas iniciativas espalhadas por todo o país. Vale a pena conhecer esse valioso recurso informacional e solidarizar-se com a luta valorosa desses tantos concidadãos.

Em diversos outros campos de atividade, também se identificam esforços que incentivam e orientam a organização social no sentido de buscar a melhoria das condições de vida e de alcançar maior protagonismo. Analisar e tirar lições de casos tais como os apresentados ajuda a ampliar nossa capacidade de "leitura", facilitando o reconhecimento de processos sociais com potencial análogo, talvez em áreas como aprendizagem e cultura. Esse pode ser um ponto de partida para aqueles em condições de participar ou engajar-se de alguma forma. Injetar e reinjetar orientações e informações advindas da reflexão teórica e metodológica, em sintonia e articulação com o processo social em curso, constituiria um terreno fecundo de reflexão e atuação, seja na prática pedagógica, na ação cultural ou na pesquisa em ciências humanas e sociais.

Também no interior e no entorno da escola brasileira notadamente a da rede pública -, certamente se encontram em desenvolvimento ações e projetos que, a partir de iniciativas individuais ou de pequenos grupos, desafiam essa instituição a repensar suas formas de relação com nosso contexto social e 
econômico. A histórica dívida que o país acumulou, em termos de inclusão social e cultural, de mãos dadas com a produção de uma avassaladora exclusão econômica, constitui um cenário que demanda um maior engajamento com as perspectivas inovadoras existentes no campo das tecnologias sociais. Nesse sentido, iniciativas que compartilhem a visão de articular ação social e atividade acadêmica estabelecem ricas oportunidades para uma parceria desafiadora e criativa entre os educadores e as inúmeras comunidades cuja maior carência talvez seja descobrir as próprias possibilidades de reinventar o presente e o futuro.

No âmbito do tripé ensino-pesquisa-extensão que caracteriza o compromisso da educação universitária brasileira, Higinoet alii (38) discutem a forma pela qual a relação com a ideia de inovação precisa ser reconfigurada, rumo ao que parece ser a mais necessária e urgente reforma da nossa universidade. Dando destaque a formas inovadoras de mediação informacional observadas em algumas ações do campo das tecnologias sociais, os autores ponderam potencialidades, contradições e desafios, em busca de caminhos para uma maior articulação dos projetos e programas institucionais com dinâmicas sociais aptas a criar, nos dias de hoje, condições para a emergência de novos movimentos de protagonismo.

\section{Dança: entre o individual e o social}

No campo do debate científico, precisamente o conceito de emergência serve de base ao entendimento de fenômenos de difícil explicação, tais como vida e consciência. Derivando da noção de complexidade, ele remete a teorizações e análises de grande fecundidade, oriundas de campos diversos, conectadas a nomes tais como o sociólogo e filósofo Edgar Morin, o antropólogo stephen Lansing e o cientista de redes Duncan Watts. Por sua vez, ao seguir uma pista de Mallarmé e propor a dança como metáfora, numa análise de cunho semiótico, Helena Katz (39) também leva as reflexões sobre corpo e dança a um domínio teórico fortemente marcado pelas noções de informação, redes e complexidade. Vê-se, nas entrelinhas, uma aproximação com a idéia de emergência.

É nesse domínio da dança como linguagem e metáfora que encontramos ricas possibilidades de leitura para a proposta dos bailarinos do projeto Imagens Deslocadas. Em sua atividade, vê-se uma clara expressão de noções tais como realimentação e autoorganização, o que leva a vislumbrar aproximações promissoras entre a experiência que vivenciaram e as dinâmicas criativas dos sistemas adaptativos complexos, das redes sociais e dos ambientes ecológico-informacionais. No 
processo i(n) terativo que conecta e compõe esse coletivo, por meio da tecnologia das Vídeo-Cartas, é interessante observar como emergem a informação e a performance - que, não por acaso, compartilham raízes etimológicas -, de modo não programado, do interior da micro-rede de indivíduos e relações que os bailarinos constituem e no âmbito das macro-redes sociotécnicas nas quais estes se inserem. Os movimentos conformam-se e, eventualmente, reformam-se na e pela interação cíclica estabelecida, conduzindo a sequências de uma riqueza virtualmente imprevisível. Esse é um padrão totalmente distinto do observado quando está em jogo uma coreografia prescrita, programada.

No âmbito das dimensões específicas da informação, dá-se um complexo entrelaçamento que estabelece um circuito físico/cognitivo/social, aos moldes daquilo que discute Edgar Morin. Numa primeira formulação, essas dimensões parecem associáveis, respectivamente, aos aspectos técnicoinstrumental, perceptivo-emocional e performático-interativo, todos eles também multiplamente interligados no fazer de cada bailarino e no processo coletivo.

Abordagens inspiradas no pensamento complexo são também fecundas para a reflexão sobre as possibilidades abertas, em campos tais como o da escola, quando se buscam métodos baseados em concepções pedagógicas não-prescritivas (40). Nesse âmbito, como nas artes, nas ciências e em outras áreas da atividade humana, a repetição e a legitimação de práticas geram padrões que, num sentido lato, produzem movimentos e criam "escolas". Nesse sentido, cânones e clássicos são portadores de significações sociais historicamente constituídas e suscetíveis, portanto, de passarem por situações de afirmação assim como de questionamento. Em algum ponto desse movimento criativo/destrutivo - a "dança de Shiva" do mundo sociocultural -, inseriu-se, historicamente, o próprio surgimento da dança contemporânea, contexto do trabalho dos bailarinos do Movasse.

O caminho da metáfora criativo-processual leva também a ver como danças as muitas sequências de "passos" que, em múltiplas escalas de tempo e em espaços diversos, constituem as performances que moldam os caminhos do mundo. Por essa via de reflexão, é possível falar numa dança dos processos históricos, numa dança dos movimentos sociais, numa dança de indivíduos e coletividades... 


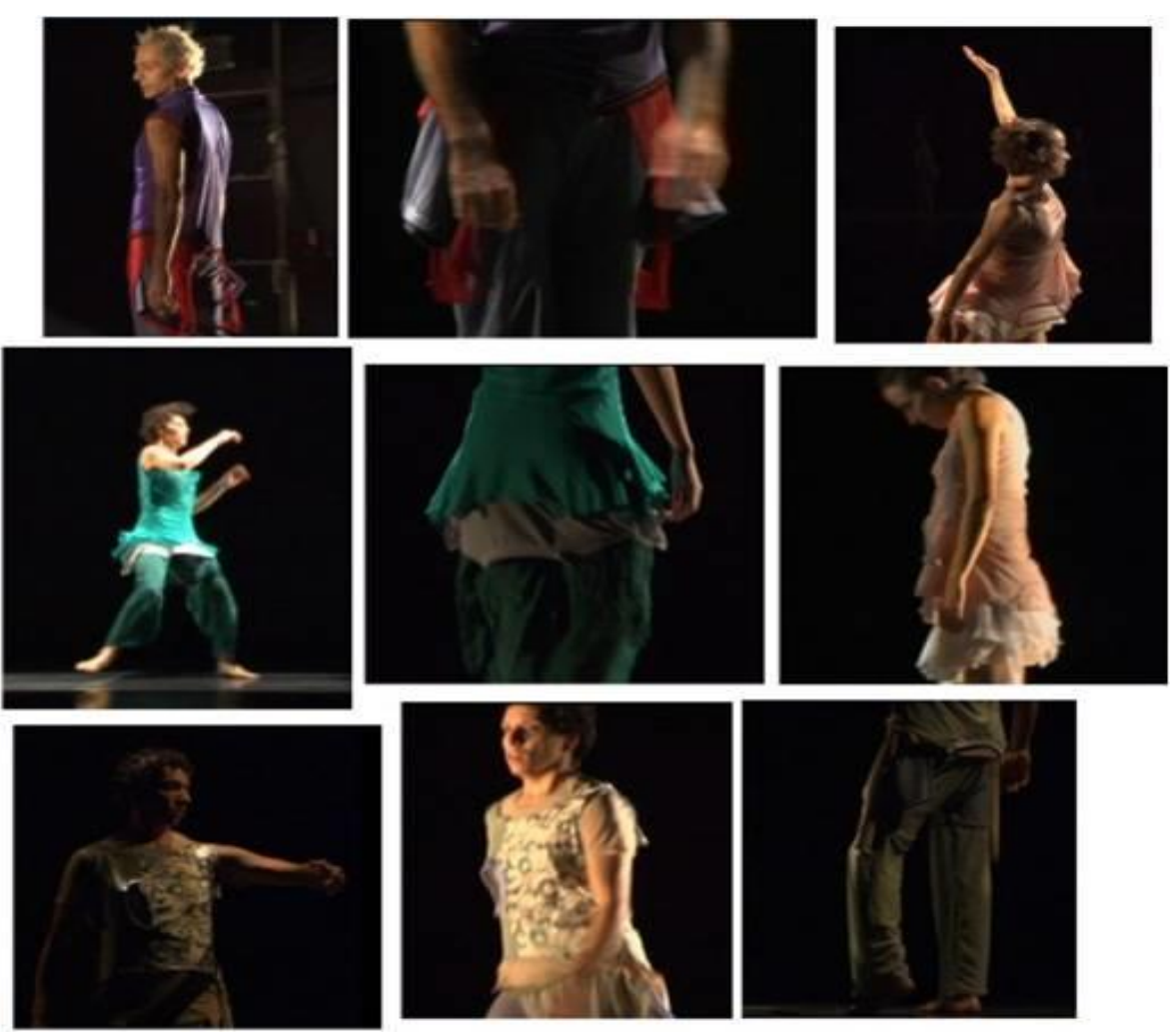

Figurino deslocado

\section{Fecham-se as cortinas: danças e mudanças}

Com essas imagens em mente, somos levados a cerrar as cortinas dos olhos e a imaginar um mundo de danças menos prescritivas e mais inspiradas em dinâmicas autocriadoras e autoorganizativas; que propicie melhores mesclas de potências autônomas e forças heterônomas; no qual a luta pela expressão subjetiva mais profunda faça par com a defesa do ser e do estar de todo outro.

Distante como ainda seja, esse mundo-imagem instiga a pensar a ação individual e dos coletivos cidadãos e campesinos como uma microdança que deve reunir uma pletora de elementos: informação, sensibilidade social, crítica, ação, reação, colaboração, competição, compromisso, resistência, persistência...

Os movimentos sociais e culturais, por sua vez, podem ser vistos com uma mesodança que deve resistir a reações de detração, barbarização, demonização, a fim de propor e promover uma adequada contextualização histórico-crítica e encontrar meios de produzir e reproduzir imagens e autoimagens condizentes com aquilo que dizem de si e por si, além de consequentes com o fazer que propõem ao mundo. 
$\mathrm{Na}$ sequência desse encaixe de escalas, veem-se resultarem as mudanças históricas de uma macrodança decorrente das outras, com seus tensos cenários que abrigam lentas ou explosivas coreografias, nos tempos e espaços deste planeta que coabitamos e que parece também trilhar os caminhos de sua própria dança pelo espaço afora...

\section{Résumé}

Basé sur une articulation de fondements théoriques de la sémiotique, des réseaux sociaux et de la pensée complexe, les relations qui unissent l'information et le corps dans le dialogue entre l'individu et les multiples niveaux sociaux y sont discutées. Ce parcours cyberculturel a un point de départ dans une expérience innovatrice, sur le terrain de la création chorégraphique, pour suivre immédiatement le cours des défis présents aujourd'hui dans les expériences intriquées de lecture de la réalité et de la production individuelle et collective de sens, de projets, de biographies et d'histoires.

Mots-clés: information - corps - sémiotique - réseaux - complexité cyberculture - mouvements sociaux.

\section{Abstract}

Based on theoretical notions from semiotics, social networks and complex thinking, we discuss the relations between information and body, in the perennial context of dialog that links together individuals and multiple levels of social organization. Our cybercultural journey departures from an innovative experiment on choreographic creation and takes us to the complex challenges that are present in nowadays intricate experiences of reality reading and individual-collective production of senses, projects, biographies, and histories.

Key-words: information - body - semiotics - networks -complexity cyberculture - social movements.

\section{Notas}

[*] O autor registra agradecimentos ao CEFET-MG e à CAPES, pelo apoio à realização do doutorado no PPGCI/UFMG.

[01] Artigo elaborado a partir do texto de sistematização do seminário "Informação e Corpo", apresentado no segundo semestre de 2006, na disciplina Fundamentos Sociais da Informação do Programa de Pós-Graduação em Ciência da Informação, da Escola de Ciência da Informação da UFMG (PPGCI/UFMG). Os autores expressam sua gratidão à Profa. Dra. Alcenir Soares dos Reis, pelo acolhimento do tema e pelas enriquecedoras sugestões, assim como à Profa. Dra. Maria Aparecida Moura, por ter aberto caminho às discussões sobre o corpo na Ciência da Informação.

[02] LEMOS, 2002.

[03] Vídeo-Carta foi o nome dado originalmente, pelo grupo Movasse, ao formato elaborado para uso no processo de criação descrito aqui. Em atenção a esse fato, optamos por manter a grafia original do termo, não a adaptando à nova ortografia da Língua Portuguesa.

[04] Projeto Nós em Rede - entrevistas, PARTE 1. Disponível

em:http://www youtube.com/watch?v=1IdIU000KeE. Acesso em: 01 dez. 2009.

[05] KATZ, 2003.

[06] KATZ, 2003, p. 263.

[07] KATZ, 2003. 
[08] PINTO, 1996.

[09] PINTO, 1996.

[10] KATZ, 2003.

[11] KATZ, 2003.

[12] PINTO, 1996.

[13] COUCHOT, 2003.

[14] COUCHOT, 2003.

[15] CUCHE, 2002.

[16] COUCHOT, 2003.

[17] Ao mencionar que o signo nunca é percebido de maneira cabal, Júlio Pinto (1996) propõe o seguinte trocadilho: ... ele não signi-fica, ele signi-vai.

[18] ARAÚJO, 2003; TOURAINE, 2006.

[19] KEHL, 2003.

[20] PILLA, 2003.

[21] CUCHE, 2002 .

[22] TOURAINE, 2006.

[23] SANTOS, 2004.

[24] HIGINO et alii, 2008.

[25] MORIN, 2000.

[26] BENJAMIN, 1996.

[27] MORIN, 1986.

[28] MORIN, 1986.

[29] KATZ, 2003.

[30] PINTO, 1996.

[31] MORIN, 1986, 1996, 2000.

[32] JACOB; ALBRECHTSEN, 1998.

[33] RODA VIVA, 2002; MANZO, 2006; SIQUEIRA, 2006; PACHECO, 2006.

[34] Banco Palmas. Endereço

eletrônico: http://www.bancopalmas.org/site.php. Acesso em: 20 nov. 2009.

[35] AGÊNCIA NORDESTE, 2004; BANCO PALMAS, 2009; NASSIF, 2009.

[36] Fórum Brasileiro de Economia Solidária. Disponível

em:http://www.fbes.org.br/index.php?option=com_frontpage\&Itemid=1. Acesso em: 20 nov. 2009.

[37] Farejador da Economia Solidária. Disponível

em:http: / /www. fbes.org.br/index.php?option=com_content\&task=view\&id=3748\&It emid=223\&Itemid=223. Acesso em: 20 nov. 2009.

[38] HIGINO et alii, 2009.

[39] KATZ, 2003.

[40] HIGINO, 2002 .

\section{Referências bibliográficas}

AGÊNCIA NORDESTE. Bairro de Fortaleza cria moeda própria. Terra Networks Brasil, 29 jun. 2004. Disponível em:http://noticias.terra.com.br/brasil/interna/0, , OI334205-EI306,00.html. Acesso em: $20 \quad$ nov. 2009. ARAÚJo, Carlos Alberto Ávila. A ciência da informação como ciência social.Ciência da Informação Online, Brasilia, v. 32, n. 3, p. 21-27, set./dez. 2003 . Disponível em: http://revista.ibict.br/ciinf/index.php/ciinf/article/view/29. Acesso em 15 nov. 2009. BANCO PALMAS. Apresenta informações sobre o Banco da Associação dos Moradores do Conjunto Palmeira - Fortaleza, Ceará. Disponível em:http://www.bancopalmas.org/site.php. Acesso em: 20 nov. 2009. 
BENJAMIN, Walter. O narrador: considerações sobre a obra de Nicolai Leskov. In: $\quad$ Magia e técnica, arte e política: ensaios sobre literatura e história da cultura. Tradução de Sérgio Paulo Rouanet. 7. ed. São Paulo: Brasiliense, $1994 / 10^{a}$ reimpressão, 1996. (Obras escolhidas, v. 1). p. 197-221.

COUCHOT, Edmond. A tecnologia na arte: da fotografia à realidade virtual. Tradução de Sandra Rey. Editora da UFRGS, 2003. CuCHE, Denys. A noção de cultura nas ciências sociais. Tradução de Viviane Ribeiro. 2. ed. Bauru: EDUSC, 2002. HIGINo, Anderson Fabian Ferreira. A pedagogia de projetos na educação em ciência \& tecnologia à luz da ciência da complexidade e do conceito de negociação; estudo de caso no ensino de física dos cursos de engenharia industrial do CEFET-MG. 2002. 187 f. Dissertação (Mestrado em Educação Tecnológica) - Centro Federal de Educação Tecnológica de Minas Gerais, Belo Horizonte, 2002. HIGINO, Anderson Fabian Ferreira; ARAÚJO, Ronaldo Ferreira; SCOTT, Carolina de Souza Paes. Construção de políticas de informação: aspectos epistemológicos e metodológicos. Liinc em Revista Online, v. 4, n. 2, set. 2008, p. 286-302. Disponível em:http://revista.ibict.br/liinc/index.php/liinc/article/viewFile/283/176. Acesso em: $20 \quad$ nov. 2009. HIGINO, Anderson Fabian Ferreira; REIS, Alcenir Soares dos; DUMONT, Lígia Maria Moreira; PEREIRA, Maria Antonieta. Mediação informacional no contexto universidade-sociedade-inovação: potencialidades, contradições e desafios. Perspectivas em Ciência da Informação Online, Belo Horizonte, v. 14, número especial, p. 163-183, 2009. Disponível em:http://www.eci.ufmg.br/pcionline/index.php/pci/article/viewFile/924/630. Acesso em 03 dez. 2009. JACOB, Elin K.; ALBRECHTSEN, Hanne. When essence becomes function: poststructuralist implications for an ecological theory of organisational classification systems. In: WILSON, T.D., ALLEN, D.K. (org.), Exploring the contexts of information behaviour: proceedings of the Second International Conference on Research in Information Needs, Seeking and Use in Different Contexts, 13-15 August 1998, Sheffield, UK. London: Taylor Graham. p. 519534 .

KATZ, Helena. A dança, pensamento do corpo. In: NovAES, Adauto (Org.). o homem máquina: a ciência manipula o corpo. São Paulo: Companhia das Letras, 2003 . $\mathrm{p}$. $261-274$.

KEHL, Maria Rita. As máquinas falantes. In: NOVAES, Adauto (Org.). O homem máquina: a ciência manipula o corpo. São Paulo: Companhia das Letras, 2003. $\mathrm{p}$. LEMOS, André. Cibercultura, tecnologia e vida social na cultura contemporânea. 2 ed. Porto Alegre: Sulina, 2004. MANZO, Paolo. Homem de ação. Carta Capital, São Paulo, 01 nov. 2006, p. 1011 .

MORIN, Edgar. Ver? Veremos... In: MORIN, Edgar. Para sair do século XX. Rio de Janeiro: Nova Fronteira, $1986 . \quad$ p. $23-58$. MORIN, Edgar. Problemas de uma epistemologia complexa. In: ___. 0 problema epistemológico da complexidade. Lisboa: Publicações EuropaAmérica, $1996 . \quad p . \quad 13-34$. MORIN, Edgar. O pensamento complexo, um pensamento que pensa. In: MORIN, Edgar, LE MOIGNE, Jean-Louis. A inteligência da complexidade. Tradução de Nurimar Maria Falci. São Paulo: Peirópolis, 2000a. p. 197-213. MORIN, Edgar. Os sete saberes necessários à educação do futuro. Tradução de Catarina E. F. Silva e Jeanne Sawaya. 2. ed. São Paulo: Cortez, Brasília: UNESCO, 2000 b. 118

MORIN, Edgar. O desafio da complexidade. In:_. Ciência com consciência. Tradução de Maria D. Alexandre e Maria Alice Sampaio Dória. 5.ed. revista e modificada pelo autor. Rio de Janeiro: Bertrand Brasil, 2001. $\quad \mathrm{p}$. $175-193$. NASSIF, Luis. A economia solidária do Banco Palmas. Internet Group, 25 fev. 
2009. Disponível em: http://colunistas.ig.com.br/luisnassif/2009/02/25/aeconomia-solidaria-do-banco-palmas/. Acesso em: 20 nov. 2009. PACHECo, Paula. É um por todos. Cařta Capital, São Paulo, 01 nov. 2006, p. $14-15$.

PILLA, Maria Cecília Barreto Amorim. Manuais de civilidade, modelos de civilização. História em Revista, Pelotas, n. 9, dez. 2003. Disponível em :http://www.ufpel.edu.br/ich/ndh/downloads/historia_em_revista_09_maria_pil la.pdf. Acesso em 09 nov. - - 2009 . PINTO, Júlio. Semiótica e informação. Perspectivas em Ciência da Informação. Belo Horizonte, v.1, n.1, p. 87-92, jan./jun. 1996. RIBEIRO, Renato Janinie. Novas fronteiras entre natureza e cultura. In: NOVAES, Adauto (Org.). O homem máquina: a ciência manipula o corpo. São Paulo: Companhia das Letras, $2003 . \quad$ p. $15-36$. RODA VIVA: Muhammad Yunus. São Paulo: TV Cultura, 2002. 1 fita de vídeo (90 min.), VHS, son., color., legendado. SANTOS, Boaventura de Sousa. Para uma sociologia das ausências e uma sociologia das emergências. In: (Org.). Conhecimento prudente para uma vida decente: um discurso sobre as ciências revisitado. São Paulo: Cortez, $2004 . \quad$ p. 777-821. SIQUEIRA, André. Eficiência barata. Carta Capital, São Paulo, 01 nov. 2006, $\mathrm{p}$.

TOURAINE, Alain. Um novo paradigma: para compreender o mundo de hoje. Tradução de Gentil Avelino Titton. Petrópolis, RJ: Vozes, 2006.261 p. 